\section{THE PLANET FUPITER}

GIN CE the earliest days of telescopic investigation, there has never been a period in which this magnificent planet has been subjected to such an extended scrutiny as the present. Telescopes of all sizes and powers, and eyes of all degrees of sensitiveness and accuracy, are being directed night after night--or rather would be so, but for the proverbial uncertainty of our English climate-towards the splendid gem of the south-eastern heaven. Such is the natural result of that unexampled diffusion of a taste for astronomy, and of the equally unprecedented multiplication of telescopes of considerable pretensions, which is characteristic of the present time, and which is so gratifying to the lovers of physical science.

This state of things, however, it need not be said, does not date from the present appirition of the planet. It is merely a renewal of the attention which was directed to the same object during the preceding winter, and it is the character of the results obtained during that former period, which has led to the ensuing remarks.

It may be reasonably thought that a comparison of such drawings as are generally attainable, professing to represent the planet during its late appearance, is not very satisfactory; and that grea er agreement might fairly have been expected. Every observer must be presumed to have done his best : yet deviations exist of no inconsiderable magnitude. There must be some reason for these discrepancies; and it will be worth our while to inquire into their nature, while, at the same time, we would carefully avoid anything like an implied depreciation of any individual result.

In the first place, as regards colour, there is little difficulty in seeing that a considerable margin must be left for uncertainty. We meet with unpleasant statements from time to time as to the prevalence of colour-blindness, or at least what might be called colour-perversion, or colourpartiality, in some modification or other, to a greater extent than might have been supposed. And independently of this, there may be some dissimilarity of tint in images formed respectively by the achromatic and the refiector, though perhaps less than some persons might expect; since the blue rays which usually go astray in the former instrument are also absorbed by the silver film of the latter, so that there will be a prevailing complementary orange, however feeble, in the light that forms the image in either case. There will, however, be this advantageand a considerable one-on the side of the refiector, that the blue light, in place of forming an unpleasant fringe, entirely disappears, leaving a delightfully colourless field in the use of the higher powers. Refractors may also differ somewhat in their mode or degree of correction, and consequentiy in the uncompensated tint; and in either construction eye-pieces may be chargeable with deficient achromaticity. So that on the whole we can scarcely be surprised at some differences in the results as far as colour is concerned.

But there would seem to be other and more influential reasons for the want of correspondence, as affecting form and position. One may be that all observers do not see equally well : not referring by this expression to clearness of eye, though in this there may be many degrees, but to the habit of attention. Where one man, for example, merely notes concerning three or four objects that they are not all of the same size; another will almost instinctively estimate their proportionate difference in magnitude. One observer again may be impressed with the proportions of the objects, but may miss those of their mutual distances : nor, again, are the estimates of different observers equally entitled to confidence. There are eyes, too, very good ones for other purposes, which are less successful than would have been expected in the discrimination of mimute planetary markings, a fact not easy of explanation.

But besides this source of discrepancy, another cxists in the fact that all observers do not draw equally well or rather it may be feared that but few draw well at all. It is much to be regretted that a certain amount of artis. tic skill is not considered absolutely necessary in a liberal education; the advantage and pleasure derivable from it in after life are so obvious that it may well be questioned whether some of the time that is spent in mastering classical and mathematical niceties of an extremely unserviceable and unpractical nature, might not be better expended in the acquirement of the most useful art of design. It ought to be remembered, also, that not only a general facility in observation and delineation is requisite, but that something depends upon that special training which results from familiarity with the individual object. Even a careful observer, whose attention had been chiefly turned to objects of another kind, might not recognise as much of planetary markings at first, as after he had studied and learned their character; and on the other hand, a competent artist might produce inaccurate work during his early acquaintance with the telescope, simply from the unfamiliar aspect of what he has to represent, as compared with anything which he has been accustomed to delineate.

When, therefore, all these sources of discrepancy are taken into account, the differences in instruments, in eyes, in hands, and in experience, it is no longer matter of surprise that the results already obtained with regard to this planet are less satisfactory in points of mutual agreement than would have been desirable. It may be hoped, and to a certain degree expected, that we shall do better in future. Inexperience is a fault that will disappear of itself; and it would be well if the unpractised observer would be content to expend a little time and trouble in making tenta-

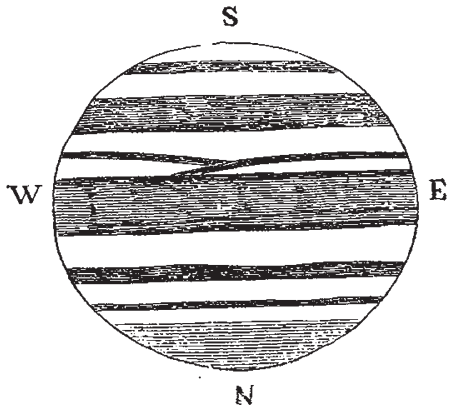

This sketch is copied from a drawing be rring the date of $1870, \mathrm{De}$ cember $14^{\mathrm{d}} \mathrm{Irh} \mathrm{IO}^{\mathrm{In}}$. It may serve as an illustration of some of these remarks, though it makes but little pretension to accuracy.

tive drawings before he considers them worthy of taking rank as representations of the planet. Imperfect attempts are, nevertheless, often deserving of preservation, as recording, as far as they go, something that may not be seen again, and thus acquiring a relative value. The remarks which follow may be thought to require some apology, especially after what has been said as to some of the causes of discrepancy; but it is hoped that their purport will not be misapprehended. It is well known that success in observation is much more readily obtained by those who have some previous idea as to what they may fairly expect to see; and on this ground the ensuing suggestions may be permitted, as the result of considerable familiarity with the object. They claim no higher character than suggestions-open as freely to contradiction as confirmation; and their object will be accomplished if they are found to give some aid to the unpractised amateur ; the skilled observer will forgive them if he finds them needless, or correct them where they may be in error. They are deduced from the observations of fortythree nights, from I 5 th October, I 869 , to $4^{\text {th }}$ April, I870, in the use of a With silvered glass spcculum of $9^{\frac{1}{3}}$ inches 
aperture and power most frequently of $2\left[2 .^{*}\right.$ For the sake of convenience we may call the dark streaks belts and the luminous ones zones; and we may divide the disc into three portions - the equatorial, the northern, and the southern region.

The equatorial region may be described as a coloured girdle surrounding the planet, and consisting of two belts with a lighter space included between them. The relative proportion of these belts--the edges of the girdle-seems not invariable, and should be noted. Especial attention should be paid also to the tint of this region, as a diminution of intensity is suspected. The centre of the girdle is one of the most interesting portions of the disc, containing a num. ber of dark markings projecting into it from the $S$. (upper as inverted) border, but not reaching the opposite N. edge, and taking the form of the piers of a bridge, or, when more fully developed or perfectly seen, of festoons, in which lighter yellow elliptical areas are included. For atmospheric phenomena, as these appear to be, they maintain a singular degree of uniformity and persistency, although their dimensions seem to vary, on different sides of the globe. An examination of earlier drawings, some of them in private hands, which I have been permitted to inspect, shows that, although at present conspicuous chiefly in the equatorial region, they are by no means restricted to that portion of the planet's surface. And here it may be noted that for the due comprehension of these details, especial attention should be paid to the laws of perspective. The foreshortening, as it is technically termed, of the regions approximating to the planet's limb, has a great infuence on the apparent form of every marking lying in a meridional direction, while the ordinary belts are entirely unaffected by it. In all probability our familiarity from early youth with the common maps of the globe in two hemispheres may tend to preoccupy us with erroneous impressions in this respect, the exterior portions of those hemispheres being projected on an entirely artificial system, which exhibits them as little foreshortened as may be, and consequently extremely unlike their natural appearance on the globe. For any one unacquainted with perspective, it would be worth while to compare the edges of such a map with the corresponding portions of a terrestrial globe, as regarded from one point of view; or a globe being surrounded with a strip of paper bearing a number of equidistant markings, it will be instructive to notice the wide change in their aspect as the globe is made to rotate on its axis. To this foreshortening, it may be noted, rather than to atmospheric obscuration, as has often been alleged, we may ascribe the invisibility of many features of the planet in the neighbourhood of the limb; the existence of an external hazy envelope may be probable, but the fading of the belts at their extremities, which has often been referred to in this light, cannot be considered conclusive; for it is remarkable that as telescopes have been improved, this alleged fading has been less spoken of. It is not at all shown in the finest drawing hitherto published (that by De La Rue), in the use of an instrument of the most critical defining power; and with my nine-inch speculum it is so doubtful under favourable circumstances that I should not have independently noted it. Attention might well be given to this point, as if a difference should be found with the same eye and telescope in different seasons, it would plainly suggest atmospheric variation.

The northern region commences with a very luminous zone, to my eye the brightest and whitest part of the disc, and usually free from interruptions. Next to this comes a belt of remarkable intensity and permanency, from the edges of which dark but short markings have been, though rarely, seen to project. Its colour formed an uniform contrast with the equatorial belts during the last season but I have thought this less striking recently. This great belt is commonly divided on the north side by a narrow light zone frum a small thin companion of uncertain

* The results have already been given in detail in the Popular Science Rerieze, July 1870 . aspect, and during the present season not invariably parallel to its overpowering neighbour ; sometimes, it is a inere edging to a streaky cap reaching to the pole, at others, a light stripe intervenes.

Passing now to the other side of the central girdle, we find next to its south border a region of some breadth, less luminous and much less tranquil than the corresponding north zone. It is interrupted by a belt of variable position and aspect, sometimes very feeble and narrow, at others a rival or more to the neighbouring edge of the central girdle. Its origin lies so close to this latter belt that it almost seems to branch out from it, and last season it followed an independent, and, in part, slightly spiral track round the greater part of the globe before its disappearance; at present I have not been able to trace its whole course, but I see that some remarkable changes have taken place. In this zone lay last winter the very curious elliptical marking described by Gledhill and Mayer, but not, I believe, by others. I never saw it, though it must have been repeatedly before my eyes-a valuable caution to myself and other students-for I had supposed myself too familiar with every portion of the disc to have overlooked so singular a feature. It is possible that my failure may have arisen from my having omitted to stop off the extreme margin of my speculum which lies quite open in its cell without any rim. I had been repeatedly requested to do so by its accomplished maker, but from want of leisure and some difficulty in the arrangement had neglected it till near the close of those observations, when the evident improvement of definition made me regret that I had recourse to the expedient so late. This precaution, which is requisite with all open specula, is in the ordinary mode of mounting rendered needless by enclosure in a cell.

South of this changeable region lies a grey belt of uncertain form and extent, sometimes divided in two, at others partially interrupted by white spots. Between this and the south pole another belt is occasionally seen, and I have thought the colouring of this and the corresponding north area, not identical. The extreme foreshortening of these regions, and the nearly vertical position of the planet's axis, must ever prevent us from obtaining much knowledge of a wide tract surrounding either pole. The north pole is at present the one more exposed, not only to our view but to solar influences; and it may be worthy of notice that there is some existing dissimilarity in the aspect of the two hemispheres. An axial inclination of little more than $3^{\circ}$ would indeed cause but little variety of season on the earth; but with the very dissimilar constitution and condition of Jupiter we know not how much may be effected by its influence.

These suggestions need not be carried into further detail. We shall however note, for the benefit of those who are little accustomed to the object, that the optical changes produced by rotation alone are such that we must be on our guard against being misled by their extent and rapidity.

\section{T. W. WEBB}

\section{NOTES}

WE have received the first Report of the Royal Commission on Scientific Instruction and the Advancement of Science just as we were going to press. We therefore let the Report, which we print elsewhere, speak for itself. We observe that it is signed by all the Commissioners, and we trust that it is the earnest of other, equally if not more important, ones to follow.

We are informed that the future of the Kew Observatory is now being considered by the Kew Committee. We would ask whether the occasion is not a fitting one to bring before the Royal Commission on the Advancement of Science, which is now sitting, the disgraceful state of this country in the matter of such 